\title{
Lightning rod system: mathematical analysis using the rolling sphere method
}

\author{
Jairo Mora Martínez ${ }^{1}$, Eliana María Noriega Angarita ${ }^{2}$, José Ricardo Nuñez Alvarez ${ }^{2}$, Michelle \\ Hernández Crespo ${ }^{3}$, Paulo José Fruto Pertuz ${ }^{3}$ \\ ${ }^{1}$ Architecture and Engineering Company, Barranquilla, Colombia \\ ${ }^{2}$ Department of Energy, Faculty of Engineering, Universidad de la Costa, Barranquilla, Atlántico, Colombia \\ ${ }^{3}$ Electrical Engineering Student, Faculty of Engineering, Universidad de la Costa, Barranquilla, Colombia
}

\begin{abstract}
Article Info
Article history:

Received Jul 3, 2021

Revised Jan 18, 2022

Accepted Jan 25, 2022

\section{Keywords:}

Atmospheric discharges

Electrical protection

Electric system

Electro-geometric method

Lightning

ABSTRACT

In electrical protection, there is a method of electrical protection of buildings against atmospheric discharges called the electro-geometric method or the rolling sphere method. So far, it is possible to achieve the implementation of this method graphically, that is, representing through plans and technical drawings, the protection conditions of the analyzed structure and obtaining from these graphic representations the protection parameters with the consequent errors caused by the scales and dimensions of the work plane. In the present work, a mathematical model is obtained that allows, using specific calculations, to analyze the dynamic behavior of a protection system against atmospheric discharges without worrying about the limitations given by the scales and planes. The set of equations obtained in the model allows us to determine the different parameters that define the protection system against atmospheric discharges (lightning) without depending on the graphical representation of the system's topology.
\end{abstract}

This is an open access article under the $\underline{C C B Y-S A}$ license.

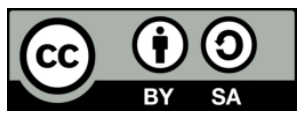

\section{Corresponding Author:}

José Ricardo Nuñez Alvarez

Energy Department, Faculty of Engineering, Universidad de la Costa (CUC)

Calle 58 \# 55-66, CP 080002, Barranquilla, Atlántico, Colombia

Email: jnunez22@cuc.edu.co

\section{INTRODUCTION}

The electrical transmission, sub-transmission, and distribution systems must guarantee the safety and reliability of the electro-energy system in case of sudden changes in voltage and current, especially when there are atmospheric discharges. It is a common practice that in the protection systems against atmospheric discharges or lightning, Franklin-type lightning rods are installed in the corners of the buildings with their respective downspouts. However, on many occasions, there is no clarity of the area protected within the zone of lightning protection [1]-[3]. Various investigations have been carried out on the protection systems against atmospheric discharges and the different methods for their calculation and dimensioning. McDonagh and Klopotan [4] a 3D algorithm is designed to apply the rolling sphere method, analyzing the structures found within the area to be protected, as well as a combination of conical, spherical, and cylindrical sections. An analysis of a lightning protection system in conjunction with a grounding system is discussed in [5] to protect offshore oil platforms (OOP).

A study that analyzes the overvoltages caused by atmospheric discharges in medium voltage lines is carried out in [6], determining the optimal location of the lightning rods to protect the transformers installed and in operation. Parise et al. [7], a study of a building in a complex of structures is presented, highlighting the worst scenarios of the impact of lightning in the implemented protection system. An investigation carried out in the pulp and paper industry is detailed in [8], where installing an external lightning protection system 
using a single pole and the independent mast is described. The study details the best location of the lightning rod system, concluding that the extended mast terminal and the rod terminal are installed in the upper structures of the recovery boiler, the chemical room, and the ovens.

Although there are standards and techniques to determine the protection systems against atmospheric discharges [9]-[16], this research work focuses its main objective on the mathematical development of the rolling sphere method, also known as the electro-geometric method, to determine the equations that they govern the behavior of the protection system and thus precisely determine the safe protection area under the electrodes or lightning rod. Usually, the electro-geometric method is used graphically [17], [18]. Still, this work proposes to find a mathematical model that consists of a set of equations that allow the calculation and design of protection systems against atmospheric discharges using only geometry analytical, trigonometry, and algebraic calculus by the rolling sphere method. In addition, different case studies are analyzed to validate the set of equations of the protection system.

The rest of this document is organized as being as. Section 2 offers an analysis of the methods most used in the calculation and design of lightning protection systems used in buildings. In section 3, the bases are created to obtain the mathematical model of the shielding system using the electro-geometric method and the rolling sphere, evaluating the proposal in two case studies. Finally, in section 4 , the conclusions are detailed according to the results obtained.

\section{METHOD}

The use of protection systems against atmospheric discharges and their different typologies are vital in interconnected or isolated electrical systems and buildings of all socio-economic sectors worldwide [19], [20]. Overvoltage is increasing in voltage that can appear on electrical distribution lines, and that can cause, among other things, damage to equipment connected to the network. Overvoltage is produced by direct and indirect lightning discharges, disconnection of inductive loads, network switching, and defects [2]. A study on the current and voltage levels of the protection system of a residential building and a nearby power line is analyzed in [21]; the authors model the system installed in the city of Huta Poreby in Poland, concluding that the value of the current between the low-voltage side and the 500-meter-long power line was only $0.02 \%$, so the impact direct lightning on the power quality is relatively small.

Naccarato et al. [22] the impact that a lightning strike produced in a residential building in the city of Sao Paulo, Brazil, in 2016 is analyzed. The authors conclude that the value of the current of the first peak saturated the Pearson sensor and that the systems ray localization (LLS) did not detect it, possibly because it had a slower pulse than the other spikes later than if the LLS detected them. Liu [23] designed software to determine the height of lightning rods with the help of the Borland $\mathrm{C}^{++}$Builder tool; with this program, it is possible to determine the height of one or more lightning rods using the polygonal method. For the verification, they used several examples, concluding that after comparing and verifying the results, the software is reliable and greatly reduces the calculation load during the design of lightning rods.

A study on lightning protection systems in heritage monuments is presented in [24], where the modified rolling sphere method (MRSM) is used. In the research, the location of vulnerable points that can be hit by lightning is analyzed and, therefore, the area of the lightning rods is obtained according to the rolling sphere method (RSM) by which the impact distance is in as a function of the value of the electric current; however, the model ignores the dynamics of propagation and the geometry of the structure. Spunei et al. [25] the damage that has occurred to the equipment and household appliances in an apartment building that has a protection system against atmospheric discharges is analyzed, concluding that it is necessary to update the standards of protection systems in buildings of more than 20 years old and placing protective screens near the electrical network to limit the induced voltage, in addition, they recommend installing the grounding conductor at a greater distance from the building in these types of constructions.

Aslani et al. [26], by using the leader progression model (LPM) in 3D space together with an intelligent algorithm called teaching-learning based optimization (TLBO), propose a new method to identify vulnerable areas with the highest probability of lightning strikes. Using the TLBO algorithm, they define a new method to determine the critical current range and determine the most vulnerable points of the structure. The best lightning rod positions can be specified based on the simulation results. A sample of the asymmetric structure of height less than 60 meters is analyzed as a case study. The optimal locations and heights of the lightning rods are determined using the RSM and the proposed method, respectively. The simulation results validate the effectiveness of the proposed method, which makes it suitable for other complex structures. A study of the RSM and the Angle method [27], [28] to design protection systems against the direct incidence of atmospheric discharges on structures. This study shows, through mathematical modeling, that both methods are closely linked and that they can be used safely in the dimensioning of protection systems since they comply with the technical requirements demanded by the standards [29]-[33]. 


\section{RESULTS AND DISCUSSION}

Depending on the geographical location of the country in which the design of the protection system against atmospheric discharges is carried out, different ways can be found to carry out the design and calculation of the protection or shielding system [9], [10], but be it whichever method is used, in general, all are based on the distance traveled by the ray tracer to contact the surface to determine the protected area [11]. The distance traveled by the ray tracer is determined considering the risk level of the structure. It can be calculated using the standards International Electrotechnical Commission (IEC) 62305-2 [12], negative temperature coefficient (NTC) 4552-2 [13]-[16], or another international standard that contemplates it.

\subsection{Electro-geometric method}

According to the technical standard NTC 4552 [13] to analyze the action of atmospheric discharges, the electro-geometric model initially developed by [16], [17] is used and which has its application in the study of the shielding or protection provided by vertical rods and conductors horizontal. Considering the dielectric breakdown voltage between electrodes installed in large spaces, an empirical equation has been established that depends on the lightning return current $\left(i_{\max }\right)$, proportional to the radius of a wait that rotates around the pick-up point, generating an area of protection $\left(r_{s c}\right)$. The equation that defines this radius is given in NTC 4552 by (1) [13].

$$
r_{S C}=2 i_{\text {Max }}+30\left(1-e^{-\frac{i_{\max }}{6.8}}\right)
$$

Where:

$r_{s c}$ : Radius of the rotating sphere around the pickup terminal and meters $i_{\text {max }}$ : Lightning return electric current and amps

This expression can be simplified is being as (2).

$$
r_{s c}=10\left(i_{\max }\right)^{0.65}
$$

Following the provisions of standard NTC 4552-2 [13]-[16], Table 1 shows the radius of the sphere of protection $\left(r_{s c}\right)$ according to the calculated risk level and the type of building where it is located installed protection system. In practice, to graphically determine the minimum height of the protection devices, circumferential arcs with radius equal to the impact distance $r_{s c}$ are drawn between the objects to be protected and the interception devices, for example, Franklin-type devices, in such a way that is tangent to the ground and to the targets that make up the arc. Any object in the line that describes the arc will be exposed to direct electrical discharges [18]. Figure 1 shows the concept of the electro-geometric model.

Table 1. Risk levels according to the characteristics of the building

\begin{tabular}{ccc}
\hline Risk level & $r_{s c}$ (meters) & $r_{s c}$ (feet) \\
\hline Level I & 35 & 115 \\
Level II & 40 & 131 \\
Level III & 50 & 164 \\
Level IV & 55 & 180 \\
\hline
\end{tabular}

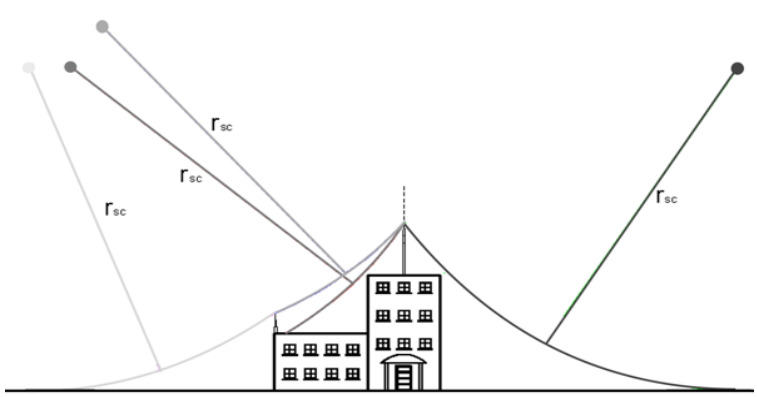

Figure 1. Schematic of the electro-geometric model

\subsection{Rolling sphere method}

The RSM is a corollary of the electro-geometric method and consists of assuming a sphere of radius equal to the impact distance that rolls over the structures to be protected [21]. The radius of the rotating

Lightning rod system: mathematical analysis using the rolling sphere method (Jairo Mora Martinez) 
sphere $r_{s c}$ is determined in the same way as in the electro-geometric method, using (1) and (2). However, it is widespread to take a radius of 150 feet or 45.72 meters as a reference. Figure 2 shows that the central or maximum circumference of a sphere has the largest radius, while any circumference parallel to it will have a smaller radius. When a sphere lies on two specific points that belong to the same plane that contains the sphere's center, it can be said that these two points belong to the central circumference. If these two points are not in the plane containing the sphere's center, the generated circumference will have a radius smaller than the maximum. When it is known, with the maximum diameter of the sphere, it is possible to simplify the mathematical model by posing the equations that can be used to determine the optimal distances between two consecutive points (electrodes of the protection system).

Figure 3 describes the sphere's movement on the structure of a multi-level building; said sphere must roll contacting the tips of the pickup terminals and finally reach the ground without contacting the structure, thus creating what is known as a protected area. The rolling sphere method should not only be applied to the building but also across the width of the structure to be protected [22], [23]. Considering the diameter of the rolling sphere, the calculations can be simplified since when it contacts any of the pick-up points, it will do so at some point on the circumference. This simplification is valid because the sphere from its center to any point on its surface will have a radius equal to $r_{s c}$.

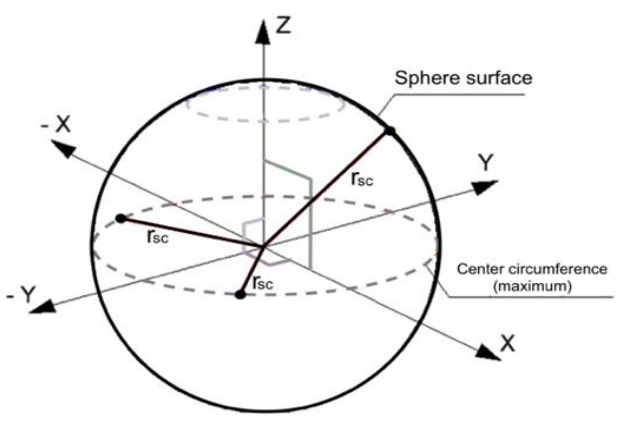

Figure 2. Cross-section of a sphere that describes a circle

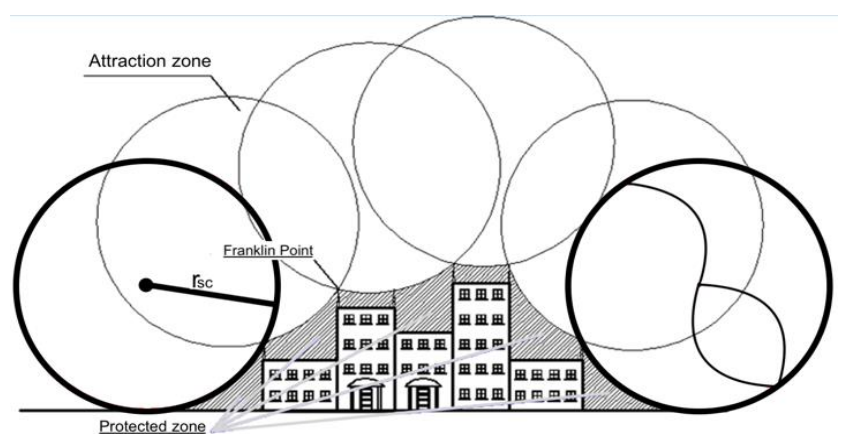

Figure 3. Schematic of the RSM

\subsubsection{Sphere that travels between the ground and a collection tip}

When analyzing this case study, it can be observed that there are three critical physical points, the center of the sphere, the point where the sphere touches the ground, and the point where the sphere contacts the lightning rod, see Figure 4. By locating the coordinate axis in a convenient position for analytical calculation, the center of sphere $\mathrm{C}$ is identified as having coordinates $\mathrm{C}=\left(0, r_{s c}\right)$. Also, the point where the rolling sphere touches the earth has coordinates $D=(0,0)$ and is the point where the coordinate axis of the system is placed. Finally, point $\mathrm{P}$, which is located at the tip of the lightning terminal (lightning rod) with coordinates $\mathrm{P}=\left(\mathrm{L}_{1},\left[\mathrm{~h}_{1}+\mathrm{h}_{2}\right]\right)$, where $\mathrm{L}_{1}$ is the separation distance between point $\mathrm{D}$ (the point where the sphere touches the land) and the building, in meters; $h_{1}$ is the height of the building, in meters and $h_{2}$ is the height of the collector point, also in meters. These points are shown more clearly in Figure 5.

The two-dimensional equation of the sphere is given by (3).

$$
(x-a)^{2}+(y-b)^{2}=r^{2}
$$

Where:

$a$ : Value of the coordinate on the $x$-axis

$b$ : Value of the $y$-axis coordinate

$r$ : Magnitude of $r_{s c}$ according to the level of risk calculated

By replacing point $\mathrm{C}$, the center of the circumference, (3) becomes:

$$
(x-0)^{2}+\left(y-r_{s c}\right)^{2}=r_{s c}{ }^{2}, x^{2}+\left(y-r_{s c}\right)^{2}=r_{s c}{ }^{2}
$$

In (4) is used to determine the safety zones and values of the protection system.

As this equation corresponds to the mathematical expression, it is possible to determine any coordinate $(x, y)$ that belongs to said circle. 
Solving for (4) for the $x$ coordinate axis, the expression (5) is obtained:

$x=\sqrt{2 y r_{s c}-y^{2}}$

Solving for (5) for the $y$ coordinate axis and obtaining:

$$
x=\sqrt{r_{s c}^{2}-x^{2}}+r_{s c}
$$

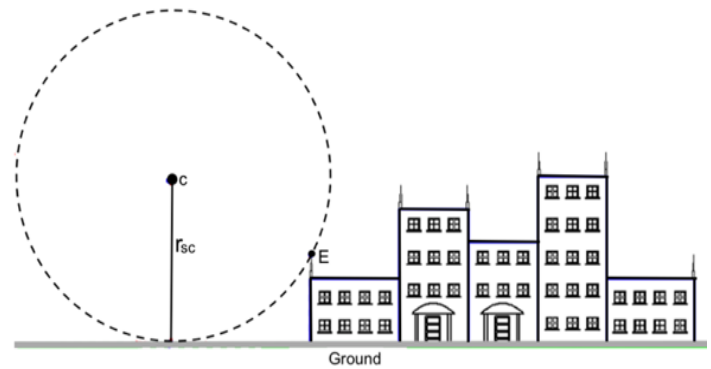

Figure 4. Case study 1: ground and catchment terminal

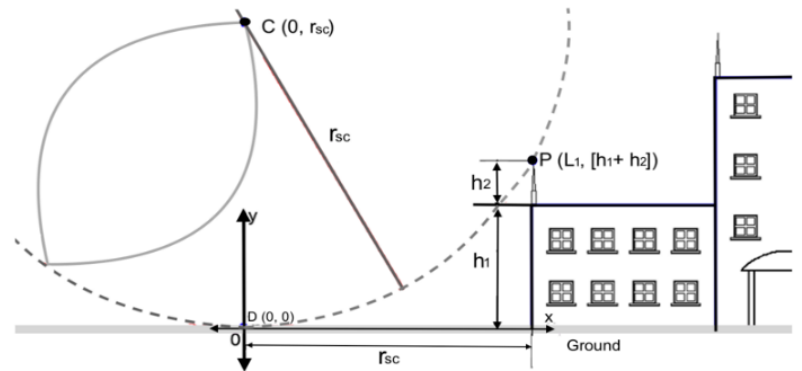

Figure 5. Case 1. Coordinates of the analysis points

With (5) and (6), it is possible to calculate the points $(x, y)$ that belong to the circumference and with which the safety parameters or the minimum distances that must be considered in the protection zone can be determined of the building. Point D shown in Figure 6 is the ground closest to the building that is most likely to be struck by lightning. Using (4), it is possible to determine its distance.

If the coordinates of point $\mathrm{P}$ are replaced in (4), the expression that allows calculating the distance between the structure and the most probable point of impact is obtained, thus obtaining (7).

$$
L_{m}=\sqrt{2\left(h_{1}+h_{2}\right) r_{s c}-\left(h_{1}+h_{2}\right)^{2}}
$$

Where:

$L_{m}$ : Distance from the building to the most probable point of impact on the ground, meters

$h_{1}$ : Height of the building to be protected, meters

$h_{2}$ : Height of the selected lightning rod, meters

After determining the maximum impact distance, the value of the physical design separation between the lightning rods of the protection system and the point of impact closest to the building must be calculated. For the design separation $\left(L_{d}\right)$ calculation, a new factor is introduced, called the safety factor $\left(f_{s}\right)$, which determines the percentage that the design separation $L_{d}$ can be increased before reaching the impact separation $L_{m}$. To determine $L_{d},(8)$ is used:

$$
L_{d}(1+f s)=L_{m}
$$

Where, $0<f_{s}<1$

From the previous equation, it is possible to solve for the design separation $L_{d}$, and we obtain (9).

$$
L_{d}=\frac{L_{m}}{(1+f s)}
$$

Another aspect to take into account is the protected separation $\left(L_{s}\right)$, which is the difference between the impact separation value $\left(L_{m}\right)$ and the design separation point $\left(L_{d}\right)$, and can be calculated by $(10)$.

$$
L_{s}=L_{m}-L_{d}
$$

We also have to analyze the protected height $\left(h_{p}\right)$, the value of the existing separation between the ground, and the point of the rolling sphere where the earth and the lightning rod (lightning rod) make contact. In Figure 7, the height $h_{p}$ is represented, and it is also observed that the value of the $\mathrm{x}$-axis $=L_{d}$. 


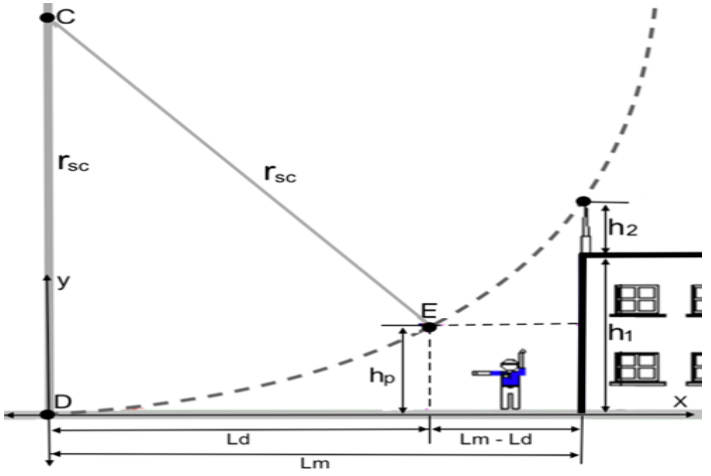

Figure 6. Case 1. Coordinates of any point $(x, y)$

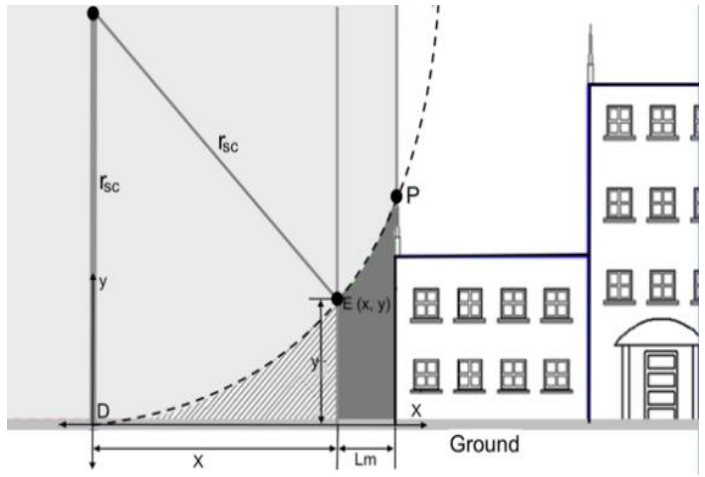

Figure 7. Protected height $h_{p}$

To calculate the protected height $h_{p}$, the value of the coordinate $x$ is replaced in (5), obtaining the expression (11).

$$
h_{p}=-\sqrt{r_{s c}^{2}-\left(L_{d}\right)^{2}}+\mathrm{r}_{\mathrm{sc}}
$$

Where: $r_{s c}$ is the sphere's radius determined with the calculation of the risk level.

With the value obtained from $L_{m}$ in (7) and using (4) and (5), it is possible to determine any coordinate of the circumference shown in Figure 6 to analyze whether a specific area or height is protected. Figure 8 shows the importance of the security zone covered by the shielding, where a structure located next to the building can be seen; this structure represents any element, for example, a water or fuel storage tank, an antenna, and a silo. As shown in Figure 8, point $\mathrm{E}$ is exposed to the direct impact of atmospheric discharges, so it is necessary to expand the protection zone to completely cover the building and the structure next to it. The expansion of this area is achieved by increasing the height of the lightning rod, which causes the sphere to recede away from the building and expanding the protected area, thus covering the structure to be protected. In Figure 9, it is observed how as the height of the lightning rod increases, the sphere moves, and the location of point $\mathrm{E}$ changes, contacting the sphere and leaving the object within the safe zone.

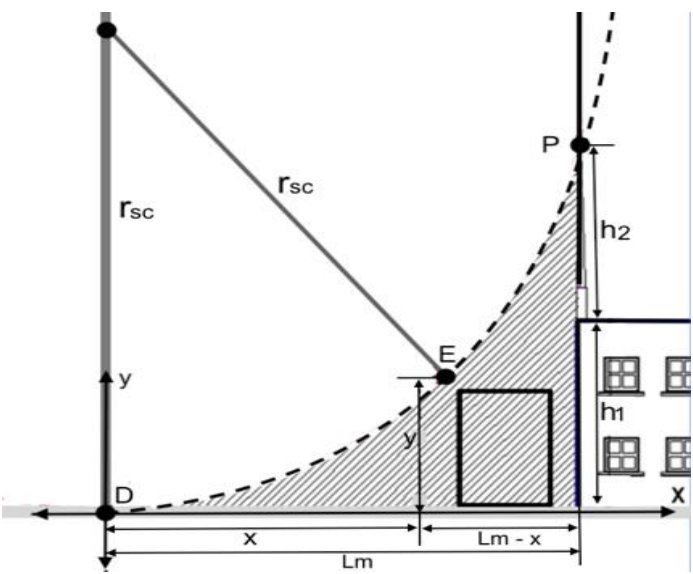

Figure 8. Unprotected structure

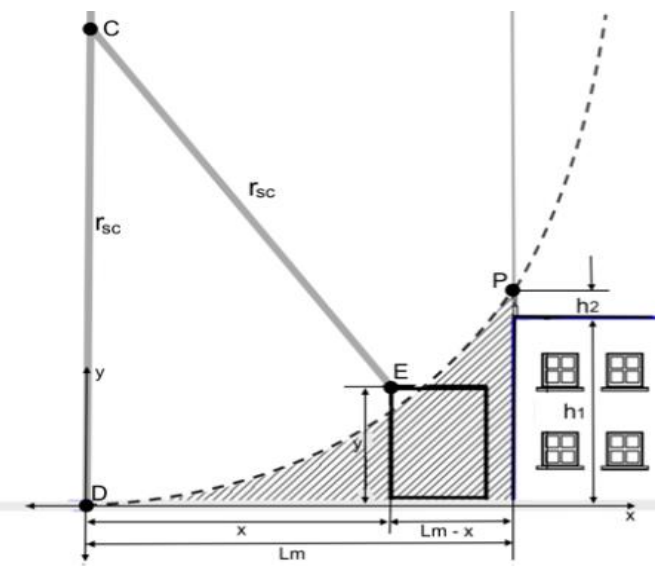

Figure 9. Protected structure

\subsubsection{Sphere supported on two points located at the same height}

The second case study is represented in Figure 10 and consists of two lightning rods separated by a defined distance. These lightning rods have the same height and contact points $\mathrm{A}$ and $\mathrm{B}$ with a sphere with center $\mathrm{C}$ and radius $r_{s c}$. Points $\mathrm{A}, \mathrm{B}$, and $\mathrm{C}$ can be analyzed as an isosceles triangle, as shown in Figure 11. The two lightning rods have a height of $\mathrm{h} 1$ and are separated by the distance L1. The sphere's point that contacts the plane where the lightning rods are located is at $\mathrm{h} 3$. The distance between points $\mathrm{A}$ and $\mathrm{C}$ and $\mathrm{B}$ and $\mathrm{C}$ is rsc, and the perpendicular distance between point $\mathrm{C}$ and line segment $\mathrm{AB}$ is $\mathrm{h} 2$. 


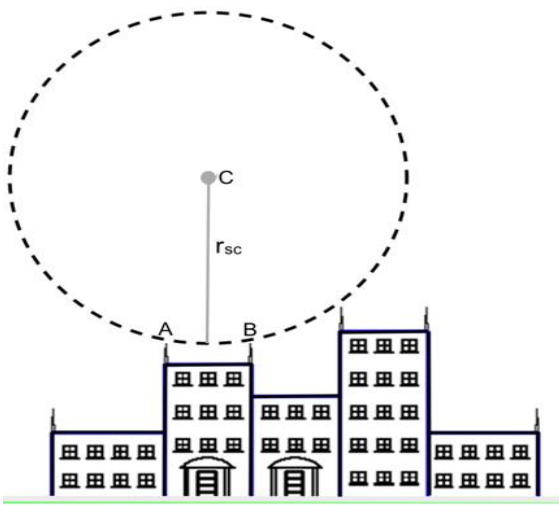

Figure 10. Sphere supported on two lightning rods that are at the same height

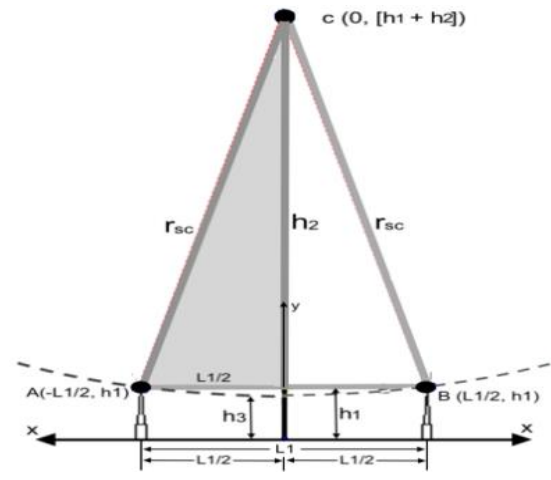

Figure 11. Case study 2. Sphere contact zone

In the system shown in Figure 11, the coordinates of the different contact points can be observed; point $\mathrm{C}$, which is the center of the circle, has coordinates $\left(0, h_{1}+h_{2}\right)$. At point $\mathrm{A}$, which is the tip of one of the two lightning rods, this coordinate is given by $\left(-L_{1} / 2, h_{1}\right)$, and at point $\mathrm{B}$, it is given by $\left(L_{1} / 2, h_{1}\right)$. The value of $h_{2}$ can be calculated with the right triangle formed between the midpoint between $\mathrm{A}$ and $\mathrm{B}$, the center $\mathrm{C}$, and point A. Applying the Pythagorean theorem for this triangle, we obtain (12):

$$
r_{s c}^{2}=\left(\frac{l_{1}}{2}\right)^{2}+h_{2}^{2}
$$

Solving for $h_{2}$ from the previous equation gives (13):

$$
h_{2}=\sqrt{r_{s c}^{2}-\left(\frac{l_{1}}{2}\right)^{2}}
$$

Working on the two-dimensional equation of the sphere shown in (4), we have:

$$
(x-a)^{2}+(y-b)^{2}=r^{2}
$$

Where $a$ is the value of the $x$ coordinate, $b$ is the value of the $y$ coordinate, and $r$ is the magnitude of $r_{s c}$ depending on the level of risk calculated.

By replacing point $\mathrm{C}$, which is the center of the circumference, (1) becomes:

$$
(x-0)^{2}+\left(y-\left[h_{1}+h_{2}\right]\right)^{2}={r_{s c}}^{2}, x^{2}+\left(y-\left[h_{1}+h_{2}\right]\right)^{2}=r_{s c}{ }^{2}
$$

In (15) is used to determine the zones and safety values of the protection or shielding system. This expression makes it possible to decide on any value corresponding to the coordinate axis $(x, y)$.

From (15), the coordinate $x$ can be solved, obtaining:

$$
x=\sqrt{r_{s c}^{2}-\left(y-\left[h_{1}+h_{2}\right]\right)^{2}}
$$

To obtain the $y$ coordinate, we have:

$$
y=\sqrt{r_{s c}^{2}-x^{2}}+\left(h_{1}+h_{2}\right)
$$

These equations make it possible to obtain the coordinates of any specific point on the circumference. To determine the value of the separation between the structure and the rolling sphere, represented by $h_{3}$ in Figure 11, the general expression given in (18) can be used.

$$
\left(h_{1}+h_{2}\right)=r_{s c}+h_{3}
$$

From the analytical point of view, it is also possible to determine the point $h_{3}$, since when the coordinate $x=0$, then $y=h_{3}$. 
By replacing $x=0$ in (17) we obtain that:

$$
y=\sqrt{r_{s c}^{2}}+\left(h_{1}+h_{2}\right)
$$

So that:

$$
y= \pm r_{s c}+\left(h_{1}+h_{2}\right), h_{3}= \pm r_{s c}+\left(h_{1}+h_{2}\right)
$$

In this case, two solutions are obtained for $x=0$, one for $+r_{s c}$, which would be the upper point of the circumference, and another for $-r_{s c}$, which would be the lower point, that is, $h_{3}$, so the final equation is given by $(21)$.

$$
h_{3}=-r_{s c}+\left(h_{1}+h_{2}\right)
$$

It should be noted that (18) is the same as (21) obtained by two different methods. Substituting (13) in (21) is:

$$
h_{1}+\sqrt{r_{s c}^{2}-\left(\frac{l_{1}}{2}\right)^{2}}-r_{s c}=h_{3}
$$

In (22) allows finding the separation $\left(h_{3}\right)$ between the rolling sphere and the structure that is being protected only with the basic design parameters, which are the height of the lightning rod $\left(h_{l}\right)$, the radius of the protection sphere $\left(r_{s c}\right)$, and the separation between the lightning rods $\left(L_{l}\right)$. An essential aspect of this case study is to determine the circumference equation when the maximum separation between lightning rods occurs, that is, to determine the maximum separation distance between lightning rods in which the rolling wait would contact the protected structure. As shown in Figure 12, the center of the circumference of the rolling sphere is located at the coordinate $\mathrm{C}=\left(0, r_{s c}\right)$. By replacing this center in $(1)$, which is the general equation of a circle, we get (4)

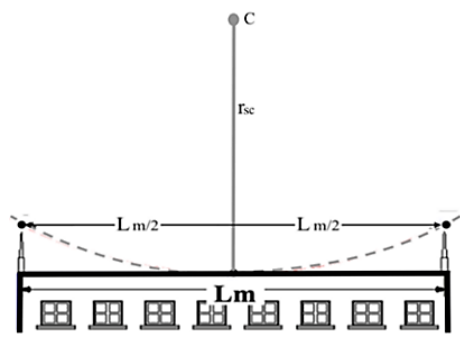

Figure 12. Maximum separation of lightning rods in a protection area

\section{CONCLUSION}

With the mathematical development carried out, it has been possible to create a new mathematical model that offers the possibility of calculating the different parameters of the lightning protection system without depending on the graphical representation of the topology of the system, which allows reducing the derived errors of the limitations of the scale on which the structure to be protected is graphed. This mathematical model is a useful tool in analyzing the different configuration cases that can occur in buildings that must be protected against atmospheric discharges without leaving unprotected areas. In the same way, it allows the designer of the protection system to have a precise dimensioning of the location of the different elements of the system. This mathematical model provides a tool that allows the design of computer applications (software) to calculate the protection system against atmospheric discharges using the rolling sphere method and considering the safety criteria according to the current technical regulations of each country. In addition, the change in the design variables of the system allows modeling different configurations to determine the most suitable and efficient one.

\section{REFERENCES}

[1] A. Mullo, V. Javier, M. Jiménez, M. Pilatasig, and H. Iturralde, "Analysis of the incidence of grounding with high resistivity against atmospheric discharges in the sub - Transmission line of $69 \mathrm{KV}$ San Rafael - Mulalo," 2017 CHILEAN Conference on 
Electrical, Electronics Engineering, Information and Communication Technologies (CHILECON), 2017, pp. 1-5, doi: 10.1109/CHILECON.2017.8229553.

[2] Y. Liu, M. Dai, A. Guha, X. Gao, and Z. Fu, "Damage Characteristics and Microstructure Response of Steel Alloy Q235B Subjected to Simulated Lightning Currents," in IEEE Access, vol. 7, pp. 9258-9264, 2019, doi: 10.1109/ACCESS.2018.2890612.

[3] V. Srinivasan, M. Fernando, S. Kumara, T. Selvaraj, and V. Cooray, "Modeling and Assessment of Lightning Hazards to Humans in Heritage Monuments in India and Sri Lanka," in IEEE Access, vol. 8, pp. 228032-228048, 2020, doi: 10.1109/ACCESS.2020.3046100.

[4] N. McDonagh and D. Klopotan, "The development of a 3-D rolling sphere algorithm for lightning protection," 2012 47th International Universities Power Engineering Conference (UPEC), 2012, pp. 1-5, doi: 10.1109/UPEC.2012.6398643.

[5] L. A. Salgado and F. Brito, "Protection system against atmospheric discharges in offshore oil platforms," 2015 IEEE Thirty Fifth Central American and Panama Convention (CONCAPAN XXXV), 2015, pp. 1-6, doi: 10.1109/CONCAPAN.2015.7428445.

[6] C. A. Christodoulou, V. Vita, and T. I. Maris, "On the optimal placement of surge arresters for the efficient protection of medium voltage distribution networks against atmospheric overvoltages," 2019 54th International Universities Power Engineering Conference (UPEC), 2019, pp. 1-4, doi: 10.1109/UPEC.2019.8893622.

[7] G. Parise, L. Martirano, and M. Lucheroni, "Level, Class, and Prospected Safety Performance of a Lightning Protection System for a Complex of Structures (LPCS)," in IEEE Transactions on Industry Applications, vol. 46, no. 5, pp. 2106-2110, Sept.-Oct. 2010, doi: 10.1109/TIA.2010.2059370.

[8] R. Zoro, K. E. Widodo, and H. Laksmiwati, "External Lightning Protection System at Pulp and Paper Industry in Areas with High Lightning Density," 2018 Conference on Power Engineering and Renewable Energy (ICPERE), 2018, pp. 1-5, doi: 10.1109/ICPERE.2018.8739688.

[9] J. C. Mora, et al., "On the use of reference areas for prospective dose assessments on populations of wildlife for planned atmospheric discharges around nuclear installations," Environmental Research, vol. 182, p. 109057, 2020, doi: 10.1016/j.envres.2019.109057.

[10] H. Hu, R. Luo, M. Fang, S. Zeng, and F. Hu, "A new optimization design for grounding grid," International Journal of Electrical Power \& Energy Systems, vol. 108, pp. 61-71, June 2019, doi: 10.1016/j.ijepes.2018.12.041.

[11] M. Rock, K. Müller, E. Shulzhenko, and R. Schünge, "Mesh width of ground grids in shelters with small base areas for low step voltages at lightning currents," 2018 34th International Conference on Lightning Protection (ICLP), 2018, pp. 1-6, doi: 10.1109/ICLP.2018.8503353.

[12] Protection against Lightning. Part 2: Risk Management, Irish Standard, CEI EN 62305-2:2012, 2012. [Online]. Available: https://shop.standards.ie/preview/98701232548.pdf?sku=863871_SAIG_NSAI_NSAI_2054831

[13] Lightning Protection, Part 1: General Principles (1ed.), NTC 4552-1, Icontec 2008. [Online]. Available https://fdocuments.in/document/ntc-4552-1.html

[14] Protection against atmospheric electric shocks, Part 2: Risk management, NTC 4552-2, Icontec 2008. [Online]. Available: https://docplayer.es/21056730-Norma-tecnica-colombiana-4552-2.html

[15] Protection against atmospheric electrical discharges, Part 2: Risk management, NTC 4552-3, Icontec 2008. [Online]. Available: https://dokumen.site/download/ntc4552-3-a5b39ef700cfc3

[16] Protection against Lightning, Part 3: Physical damage to structures and threats to life, NTC 4552-3, Icontec 2008. [Online]. Available: $\quad$ https://fdocuments.in/document/norma-tecnica-ntc-colombiana-4552-3-sistema-de-puesta-a-tierra-usandoadecuadamente.html

[17] B. Brusso, "The Electrogeometrical Model of the Rolling Sphere Method [History]," in IEEE Industry Applications Magazine, vol. 22, no. 2, pp. 7-70, March-April 2016, doi: 10.1109/MIAS.2015.2503940.

[18] W. Brooks et al., "Investigation of Lightning Attachment Risks to Small Structures Associated with the Electrogeometric Model (EGM)," in IEEE Transactions on Plasma Science, vol. 48, no. 6, pp. 2163-2174, June 2020, doi: 10.1109/TPS.2020.2989664.

[19] I. Petrović, S. Nikolovski, H. R. Baghaee, and H. Glavaš, "Determining Impact of Lightning Strike Location on Failures in Transmission Network Elements Using Fuzzy Decision-Making," in IEEE Systems Journal, vol. 14, no. 2, pp. 2665-2675, June 2020, doi: 10.1109/JSYST.2019.2923690.

[20] H. Hu, M. Fang, Y. Zhang, L. Jing, and F. Hu, "Dynamic lightning protection method of electric power systems based on the large data characteristics," International Journal of Electrical Power \& Energy Systems, vol. 128, p. 106728, June 2021, doi: 10.1016/j.ijepes.2020.106728.

[21] G. Maslowski and S. Wyderka, "Modeling of Currents and Voltages in the Lightning Protection System of a Residential Building and an Attached Overhead Power Line," in IEEE Transactions on Electromagnetic Compatibility, vol. 62, no. 5, pp. 2164-2173, Oct. 2020, doi: 10.1109/TEMC.2020.2982127

[22] K. P. Naccarato, A. R. de Paiva, M. M. F. Saba, C. Schumann, J. C. O. Silva, and M. A. S. Ferro, "Preliminary comparison of direct electric current measurements in lightning rods and peak current estimates from lightning location systems," 2017 International Symposium on Lightning Protection (XIV SIPDA), 2017, pp. 319-323, doi: 10.1109/SIPDA.2017.8116944.

[23] W. L. Liu, "The Methods of Calculating Heights of Lightning Rods and the Design of the Calculating Software," Lecture Notes in Electrical Engineering, vol 585, pp. 965-975, 2019, doi: 10.1007/978-981-13-9783-7_79.

[24] V. Srinivasan et al., "Three-Dimensional Implementation of Modified Rolling Sphere Method for Lightning Protection of Giant Medieval Chola Monument in South India," 2019 14th Conference on Industrial and Information Systems (ICIIS), 2019, pp. 535540, doi: 10.1109/ICIIS47346.2019.9063330.

[25] E. Spunei, I. Piroi, and F. Piroi, "Finding the Minimal Fitting Distance of a Lightning Rod Down-Conductor," 2019 International Conference on Electromechanical and Energy Systems (SIELMEN), 2019, pp. 1-4, doi: 10.1109/SIELMEN.2019.8905894.

[26] F. Aslani, M. Yahyaabadi, and B. Vahidi, "A new-intelligent method for evaluating the lightning protection system performance of complex and asymmetric structures," Elec. Power Syst. Res., vol. 190, p. 106843, Jan. 2021, doi: 10.1016/j.epsr.2020.106843.

[27] B. R. de Araújo, "Mathematical modeling for analysis and design of LPS: Angle method," 2017 International Symposium on Lightning Protection (XIV SIPDA), 2017, pp. 42-48, doi: 10.1109/SIPDA.2017.8116897.

[28] Z. S. Hussain, A. J. Ali, A. A. Allu, and R. K. Antar, "Improvement of protection relay with a single phase auto-reclosing mechanism based on artificial neural network," International Journal of Power Electronics and Drive Systems (IJPEDS), vol. 11, no. 1, pp. 505-514, March 2020, doi: 10.11591/ijpeds.v11.i1.pp505-514.

[29] S. Díaz, J. Nuñez, K. Berdugo, and K. Gomez, "Study of technologies implemented in the operation of SF6 switches," IOP Conf. Ser.: Mater. Sci. Eng., vol. 872, no. 1, p. 012041, 2020, doi: 10.1088/1757-899X/872/1/012041

[30] F. Grau, J. Cervantes, L. Vázquez, and J. R. Nuñez, "Effect of LED Technology on Technical Losses in Public Lighting Circuits. A Case Study," Journal. of Engineering Science and Technology Review, vol. 14, no. 2, pp. 198-206, 2021, doi: 10.25103/jestr.142.24 
[31] J. Andramuño, E. Mendoza, J. Núñez, and E. Liger, "Intelligent distributed module for local control of lighting and electrical outlets in a home," J. Phys.: Conf. Ser., vol. 1730, no. 1, p. 012001, 2021, doi: 10.1088/1742-6596/1730/1/012001.

[32] J. Nuñez, I. F. B. Pina, A. R. Martínez, S. D. Pérez, and D. L. de Oliveira, "Tools for the Implementation of a SCADA System in a Desalination Process," in IEEE Latin America Trans., vol. 17, no. 11, pp. 1858-1864, 2019, doi: 10.1109/TLA.2019.8986424.

[33] E. V. M. Merchán, I. F. B. Pina, and J. R. N. Alvarez, "Network of multi-hop wireless sensors for low cost and extended area home automation systems," Revista Iberoamericana de Automática e Informática Industrial (RIAI), vol. 17, pp. 412-423, 2020, doi: 10.4995/riai.2020.12301.

\section{BIOGRAPHIES OF AUTHORS}
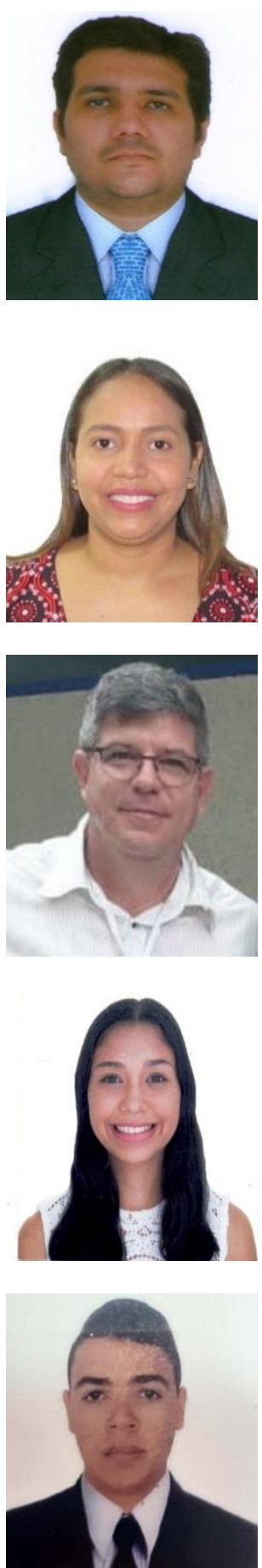

Jairo Mora Martínez (D) 8. SC P was born in Barrancabermeja, Colombia, in 1977. In 2008 he worked as an Advisor in the Risk Management Office of the Barranquilla District as an Electrical Risk Analyst for Buildings. From 2009 to 2021 he has worked in the design and construction of urban and rural electrification works, sports infrastructure and consulting in electrical infrastructure of the health sector for private companies and national concessions. He graduated as an Industrial Technician in the Specialty of Electricity in 1996 and obtained the title of Electrical Engineer in 2007. His areas of interest are Grounding and Protection Systems, Electric Power Generation, Transmission and Distribution, Renewable Sources of Electric Power and New Sources of Energy. He can be contacted at email: jairomor@gmail.com.

Eliana María Noriega Angarita (iD 8d SC P Electrical Engineer and master's in engineering, Industrial emphasis from the Universidad de la Costa, Barranquilla, Colombia. Her areas of interest are Energy Efficiency, Electrical Regulations, Renewable Energies and Generation, Transmission and Distribution of Electric Energy. She can be contacted at email: enoriega2@cuc.edu.co.

José Ricardo Núñez Alvarez (D) 8 SC P received the B.Eng. in Electrical Engineering from the Universidad de Oriente, Santiago de Cuba, Cuba, in 1994 and the M.S. degree in Automatic Engineering at the Universidad de Oriente, Santiago de Cuba, Cuba, in 2014. Currently, he is a full-time professor of the Electrical Engineering Career attached to the Department of Energy at the Universidad de la Costa (CUC), Barranquilla, Colombia. His research interests include renewable energy, power quality, power generation, power grids, power supply quality, power conversion, power transmission reliability, power system stability, power transmission lines, power transmission planning, power transmission protection, load flow control and protection of electrical systems. He can be contacted at email: ricardo10971@gmail.com.

Michelle Hernández Crespo (D) 801 SC P was born in Barranquilla in 2000. She completed her High School studies in 2017 and is currently studying Electrical Engineering in the eighth semester at the Universidad de la Costa in Barranquilla, Colombia. She can be contacted at email: mhernand55@cuc.edu.co.

Paulo José Fruto Pertuz (DD SC PC was born in Barranquilla, Colombia, in 1996. In 2013 he finished High School, then in 2017 I began my undergraduate studies at the Universidad de la Costa (CUC), Barranquilla, Colombia, where I am currently studying the eighth semester at the Faculty of Electrical Engineering, my areas of interest are: renewable energy, quality and rational use of energy and electrical installations. He can be contacted at email: pfruto1@cuc.edu.co. 